\title{
Vasculitis, CTCAE
}

National Cancer Institute

\section{Source}

National Cancer Institute. Vasculitis, CT CAE. NCI Thesaurus. Code C54741.

A disorder characterized by inflammation involving the wall of a vessel. 